\title{
Asymptomatic bronchial hyperresponsiveness in adolescents and young adults
}

\author{
B.G.M. Kolnaar*, H. Folgering**, H.J.M. van den Hoogen*, C. van Weel*
}

Asymptomatic bronchial hyperresponsiveness in adolescents and young adults. B.G.M. Kolnaar, H. Folgering, H.J.M. van den Hoogen, C. van Weel. (CERS Journals Ltd 1997. ABSTRACT: The clinical significance of asymptomatic bronchial hyperresponsiveness (BHR) is not well-known. The aim of this study was to explore, in a crosssectional analysis, the characteristics of adolescent subjects with asymptomatic BHR, as compared to nonhyperresponsive subjects and those with symptomatic BHR. The subjects were selected by date of birth from the register of general practitioners. The hypothesis that both asymptomatic and symptomatic BHR are related to early childhood lower respiratory tract infections was also tested, in a historical cohort analysis.

Respiratory morbidity was studied in early childhood and BHR in adolescence and young adulthood, in a population of 551 subjects aged 10-23 yrs. Morbidity had been recorded prospectively since birth in the general practice. Data on chronic respiratory symptoms, smoking behaviour, airways obstruction, BHR and allergy were collected during this investigation.

BHR was present in $42 \%$ of the subjects, of which $70 \%$ were asymptomatic. The occurrence of symptomatic BHR was related to acute bronchitis in early childhood, allergy, airways obstruction and recent asthma, acute bronchitis and hay fever; whereas, asymptomatic BHR was not. Characteristics of subjects with asymptomatic BHR did not differ significantly from those without BHR, with respect to these factors.

We conclude that asymptomatic bronchial hyperresponsiveness in adolescence and young adulthood is not related to lower respiratory infections in early childhood. Furthermore, subjects with asymptomatic bronchial hyperresponsiveness have similar characteristics to those without bronchial hyperresponsiveness, but differ strongly from subjects with symptomatic hyperresponsiveness. Asymptomatic bronchial hyperresponsiveness may not be the link between early childhood lower respiratory morbidity and asthma in later life, nor a risk factor for later asthma. Eur Respir J., 1997; 10: 44-50.
Depts of *General Practice and Social Medicine and **Pulmonary Diseases, Faculty of Medical Sciences, University of Nijmegen, The Netherlands.

Correspondence: H. Folgering

Dept of Pulmonology

PO Box 9001

NL 6560 GB Groesbeek

The Netherlands

Keywords: Adolescents and young adults bronchial hyperresponsiveness early childhood respiratory illnesses symptoms

Received: September 71993

Accepted after revision August 261996

This work was supported by grant No. 900715-163 of the Council of Medical Research of the Netherlands Organisation for Scientific Research and by Kabi Pharmacia B.V., Woerden, The Netherlands.
Bronchial hyperresponsiveness (BHR) is characteristic, though not specific, for asthma; it is also present in chronic airflow limitation, rhinitis and after upper or lower respiratory tract infections (LRTI) [1, 2]. In population studies, up to $58 \%$ of hyperresponsive subjects did not report respiratory symptoms [3-5]. The clinical significance of asymptomatic BHR is, therefore, still unclear. Spontaneous remissions have been reported in children $[6,7]$ but poor perception of dyspnoea has also been suggested as an explanation [8]. Other studies have demonstrated that asymptomatic BHR precedes the development of asthma $[9,10]$ suggesting that it is a risk factor for development of asthma at a later stage. If this is true, it might be expected that, with respect to asthma characteristics, subjects with asymptomatic BHR would be comparable to those with symptomatic BHR (asthma), and would differ from subjects without BHR.

ZHONG et al. [10] demonstrated an increased tendency to develop asthma in asymptomatic hyperresponsive adolescents with a history of acute respiratory illness in early childhood. This would support a theoretical model, which implies that LRTI in early childhood are a risk factor for the development of asthma [11, 12]. Acquired changes in the bronchial (sub)mucosa could manifest themselves as BHR, which may initially persist without symptoms, but may become symptomatic in later life, possibly because of environmental factors. If BHR is the essential link in the evolution from LRTI in early childhood to asthma, then this BHR should be related to the incidence of LRTI in early childhood, both for symptomatic and for asymptomatic BHR.

The aim of this study was to answer the following questions:

1. What is the prevalence of BHR, both asymptomatic and symptomatic forms, in a sample of subjects selected from registers of general practitioners on the criterion of age 10-23 yrs (hereafter, referred to as adolescents and young adults)?

2. Are both forms of BHR in adolescence and young adulthood related to LRTI in early childhood?

3. Do subjects with asymptomatic and those with symptomatic BHR have similar personal characteristics and clinical characteristics related to asthma? 


\section{Methods and materials}

A cohort of children from general practice records was followed from birth to the age of 10-23 yrs. Morbidity data was prospectively recorded from birth onwards. The respiratory status at the age of 10-23 yrs was studied by use of a questionnaire, spirometry and a histamine challenge test.

\section{Study population}

The 581 participating subjects $(40 \%$ of the original birth cohort) were recruited from the registers of the practice population of the Continuous Morbidity Registration (CMR), Department of General Practice, University of Nijmegen, The Netherlands. Subjects were recruited from these records, only on the basis of their date of birth. Under the structure of the Dutch health care system, professional medical care can only be obtained through primary care. Listing with a general practitioner is compulsory under every insurance scheme, and each general practice has a fixed, identifiable and unselected list of patients $[13,14]$.

The registration started in 1967, and the study was confined to all subjects born before 1979, to guarantee a follow-up of $10 \mathrm{yrs}$ from birth. Of the 1,441 children born during that period, 492 had left the area at the time of the study, and 23 had died of a non-respiratory cause. The remaining 926 subjects were invited to take part in the study (fig. 1). A written and oral explanation was given to the subjects, and to their parents if they were

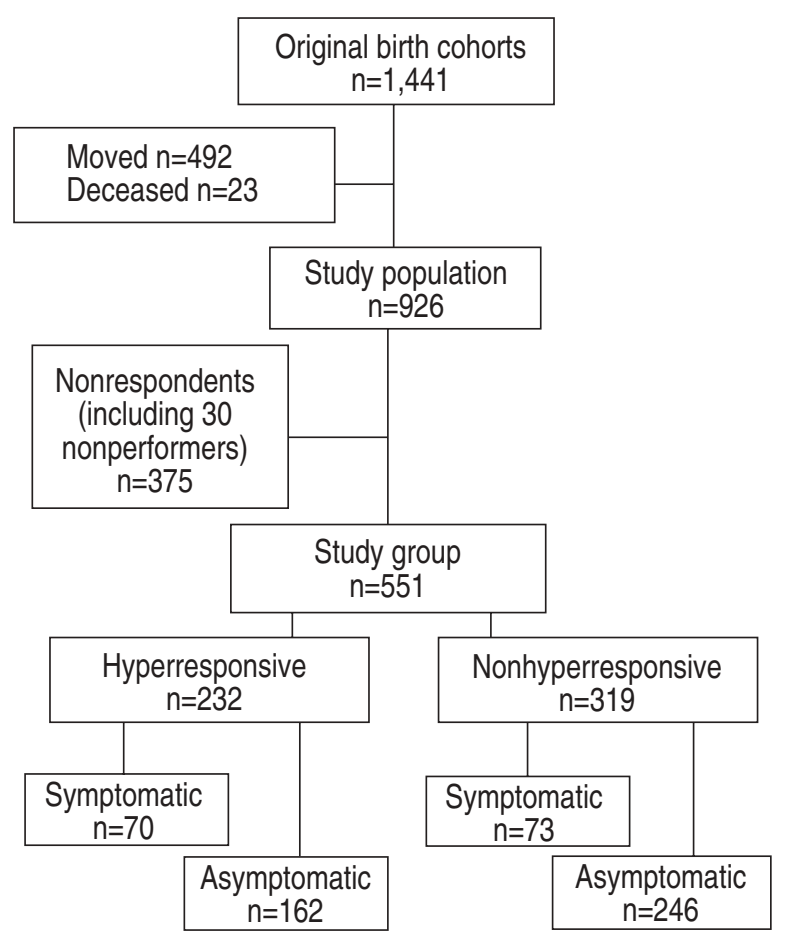

Fig. 1. - Diagram of the study group, of the original birth cohort in the open population from which it was recruited, and of the subdivisions into the hyperresponsive or nonhyperresponsive categories, with and without complaints. aged $<16$ yrs. They were asked to complete a respiratory questionnaire and to undergo spirometry and a histamine challenge test. Of this group, 581 subjects (63\%) participated in this study. The data of 30 subjects were excluded from analyses and are referred to as nonperformers: three subjects were not able to perform reproducible forced expiratory manoeuvres, seven could not finish the challenge test due to cough, although forced expiratory volume in one second (FEV1) was not significantly decreased; and 20 subjects did not complete the questionnaire satisfactorily. None of the subjects had an initial FEV $1 \leq 50 \%$ of predicted, or $\leq 1 \mathrm{~L}$, so that all 551 participants underwent the histamine challenge test.

The CMR (the characteristics have been described elsewhere) $[12,15]$ provided the following information: 1) the early childhood respiratory morbidity during the first 5 yrs of life, and the recent respiratory morbidity during the 5 yrs preceding the start of this study; 2) data on age, sex and socioeconomic status; and 3) a family history (parents or siblings) of asthma. Data of chronic respiratory symptoms, smoking behaviour, airways obstruction, BHR and allergy were collected in the winter of 1989-1990.

The questionnaire was based on the standardized questionnaire on four respiratory symptoms (children's version) of the British Medical Research Council (BMRC) and the American Thoracic Society (ATS) [16]. Its reproducibility had been found to be satisfactory [17]. All subjects completed the questionnaire by themselves.

The four questions on "chronic respiratory symptoms" are listed in table 1. A question on smoking habits was added by us. A subject was considered "symptomatic" in the case of an affirmative answer to at least one of the four questions on chronic symptoms.

Spirometry was carried out with a portable flowvolume meter (Microspiro HI-298, Chest Corp., Tokyo, Japan) [18]. Each subject had to perform three satisfactory forced vital capacity (FVC) manoeuvres (values within $10 \%$ of each other). Data were taken from the highest sum of FVC and the FEV1. Subjects who had a FEV1 $\leq(\mathrm{FEV} 1$ pred $-2 \mathrm{SD})[19,20]$ were considered to have airways obstruction.

Table 1. - Responses of the study group $(n=551)$ to questions on chronic respiratory symptoms and smoking behaviour

\begin{tabular}{lc}
\hline Question & $\begin{array}{c}\text { Positive } \\
\text { response } \\
\%\end{array}$ \\
\hline 1. $\begin{array}{l}\text { Chronic cough: did you usually - at least 5 } \\
\text { days a week - cough (e.g. when getting up, } \\
\text { or during the day, or at night) during a period } \\
\text { of at least three consecutive months? }\end{array}$ & 5 \\
2. $\begin{array}{l}\text { Chronic cough with phlegm: have you } \\
\text { coughed up phlegm, more than usually, }\end{array}$ & 7 \\
$\begin{array}{l}\text { for at least three consecutive weeks in the } \\
\text { last 12 months? }\end{array}$ & 19 \\
3. Wheezing: have you had wheezing in your \\
$\begin{array}{l}\text { chest in the last 12 months? } \\
\text { Tightness with wheezing: have you had } \\
\text { attacks of tightness with wheezing in your } \\
\text { chest (attacks of asthma) in the last 12 months? }\end{array}$ \\
$\begin{array}{l}\text { Smoking behaviour: } \\
\text { Do you smoke? }\end{array}$ \\
$\begin{array}{l}\text { Have you ever smoked, but have stopped } \\
\text { smoking? }\end{array}$ & 8 \\
\end{tabular}


The provocative concentration of histamine causing a $20 \%$ decrease in FEV1 (PC20) was assessed by means of the concise version of the European Respiratory Society standardized tidal breathing procedure [20]. The combination of nebulizer and flow meter was calibrated by a weighing method, to give an output of 0.13 $\mathrm{mL} \cdot \mathrm{min}^{-1}$. The tests were taken by field workers trained and supervised by the university lung function laboratory. International recommendations were followed exactly: the starting concentration was adapted according the FEV1, the FEV1/inspiratory vital capacity (VC) ratio, and the use of inhaled medication. Following a $2 \mathrm{~min}$ inhalation of saline, histamine concentrations of $0.03-$ $16 \mathrm{mg} \cdot \mathrm{mL}^{-1}$ were inhaled. At 30 and $90 \mathrm{~s}$ after each inhalation, the forced expiratory manoeuvres were performed to measure the response. The lowest FEV1 value from an adequate maximum expiratory flow-volume (MEFV) curve was used for further evaluation. If the change in FEV1 was less than $5 \%$, the next dose was omitted. A 5 min interval was taken between the start of inhaling two successive doses. Bronchodilators and antihistamines, when used, were withheld at least 8 and $48 \mathrm{~h}$, respectively, before the test. When a subject reported a respiratory tract infection with fever in the last 6 weeks, the test was postponed until at least 6 weeks after the end of the infection. Results were expressed as the PC20 histamine. Subjects with a PC20 $\leq 8.0 \mathrm{mg} \cdot \mathrm{mL}^{-1}$ were considered to have BHR [20].

Allergic response to inhalant allergens was assessed by the Phadiatop-test (Kabi Pharmacia Diagnostics AB, Uppsala, Sweden) [21]. The test was considered positive when the ratio (subject's serum/reference serum) was higher than 1 .

\section{Analysis}

An analysis was performed to assess whether the participants in this study formed a representative sample of the original birth cohorts. For that purpose, they were compared with those of the original birth cohorts who did not belong to the study group. The comparison was made for sociodemographic features and for respiratory morbidity recorded in the first 5 yrs of life. The children who had left the practices before the age of 5 yrs (from whom not all the necessary data were available) were, therefore, ignored in this respect.

The study group was also compared with those who were invited for the study $(n=926)$ but refused to participate ("nonrespondents", $n=375$ ) regarding the respiratory morbidity during the 5 yrs preceding the study, to assess the representativeness of the study group.

BHR was subdivided into symptomatic and asymptomatic BHR, according to the reporting of chronic respiratory symptoms. Respiratory illness episodes in early childhood were separately related to BHR, both symptomatic and asymptomatic. They were handled as dichotomous variables in a historical cohort analysis. For each relationship the relative risk (RR) and its $95 \%$ confidence intervals (95\% CIs) were assessed. The asymptomatic hyperresponsive subjects and the symptomatic hyperresponders were compared with the nonhyperresponsive group and with each other, with respect to the following personal and clinical characteristics connec- ted to asthma: sociodemographic features; recent respiratory morbidity; family history (parents or siblings) of asthma; smoking habits (ever or never); allergy to inhalant allergens; and airways obstruction. All of the characteristics were handled as dichotomous variables in a cross-sectional analysis. For each comparison the odds ratio (OR) and its 95\% CIs were assessed.

A multiple logistic regression analysis was carried out, to ensure that each factor which was found to be related to BHR remained independently related to it after controlling for the other factors (excluding recent respiratory illnesses).

The analyses were repeated using more restrictive criteria for BHR [22], namely BHR in case of PC20 $\leq 4.0$ and in case of $\leq 2.0 \mathrm{mg} \cdot \mathrm{mL}^{-1}$, since the choice of the cut-off point is arbitrary $[23,24]$. The value PC20 is reported to be dependent upon baseline airway patency [25]. In order to assess to what extent this was the case in the population of the present study, a Spearman's rank correlation coefficient was calculated between baseline FEV1 \%pred and $\log \left(\mathrm{PC}_{20}+1\right)$ for those who achieved a $20 \%$ fall in FEV1 during bronchial challenge.

A Chi-squared test was used to determine the significance of the associations and the differences. All analyses were performed using the Statistical Analysis System (SAS) package (SAS Institute Inc., Cary, NC, USA). A p-value of $<0.05$ was considered significant.

The study was approved by the Ethics Committee of the Faculty of Medical Sciences of the University of Nijmegen.

\section{Results}

The study group included significantly fewer male subjects and fewer subjects of the highest social class and presented more episodes of respiratory morbidity in early childhood, compared to those of the original birth cohort not participating in the study (table 2).

In the study group, more subjects had episodes of acute bronchitis and hay fever in the 5 years preceding the study, as compared to nonrespondents (table 3).

The distribution of $\mathrm{PC} 20$ values in the study group is shown in figure 2. BHR could be demonstrated in 232 subjects (42\% of the study group). One or more chronic respiratory symptoms were present in 143 subjects $(26 \%)$. Of those with BHR, $70 \%$ did not report any chronic respiratory symptom (fig. 1).

Table 4 shows the relationship between respiratory illnesses in the first 5 yrs of life and BHR when aged 10-23 yrs. Only acute bronchitis in early childhood was related to BHR in adolescence and young adulthood $(\mathrm{RR}=1.3 ; \mathrm{p}=0.02)$. However, this association was only present for those with symptomatic BHR.

The results of the comparisons between subject groups with asymptomatic BHR, symptomatic BHR, and nonBHR, with respect to a family history of asthma, smoking habits, presence of allergy, of airways obstruction and of recent respiratory illnesses are shown in table 5 . The comparison between subjects with asymptomatic BHR and non-BHR did not show significant differences.

In the symptomatic BHR group, more subjects had an allergy, airways obstruction or recent respiratory morbidity (namely, asthma, acute bronchitis and hay 
Table 2. - Study group $(n=551)$ compared to those lost to follow-up* $(n=214)$ and nonrespondents $(n=375)$

\begin{tabular}{|c|c|c|c|}
\hline & $\begin{array}{c}\text { Study group } \\
\%\end{array}$ & $\begin{array}{l}\text { Practice leavers and } \\
\text { nonrespondents } \\
\%\end{array}$ & p-value \\
\hline \multicolumn{4}{|c|}{ Sociodemographic features } \\
\hline \multicolumn{4}{|c|}{ Age } \\
\hline$<16$ yrs & 56 & 53 & 0.49 \\
\hline$>16 \mathrm{yrs}$ & 44 & 47 & \\
\hline \multicolumn{4}{|l|}{ Sex } \\
\hline Male & 50 & 57 & 0.03 \\
\hline Female & 50 & 43 & \\
\hline \multicolumn{4}{|c|}{ Social class } \\
\hline Upper & 6 & 10 & 0.005 \\
\hline Middle & 45 & 38 & \\
\hline Lower & 49 & 52 & \\
\hline \multicolumn{4}{|c|}{ Early childhood morbidity $0-4$ yrs $^{\#}$} \\
\hline \multicolumn{4}{|l|}{ Asthma } \\
\hline 0 & 96 & 97 & 0.30 \\
\hline$\geq 1$ & 4 & 3 & \\
\hline \multicolumn{4}{|c|}{ Acute bronchitis } \\
\hline 0 & 64 & 70 & 0.03 \\
\hline 1 & 20 & 19 & \\
\hline$\geq 2$ & 16 & 11 & \\
\hline \multicolumn{4}{|c|}{ Pneumonia } \\
\hline 0 & 91 & 93 & 0.27 \\
\hline$\geq 1$ & 9 & 7 & \\
\hline \multicolumn{4}{|l|}{ Hay fever } \\
\hline 0 & 97 & 99 & 0.02 \\
\hline$\geq 1$ & 3 & 1 & \\
\hline \multicolumn{4}{|c|}{ Otitis media } \\
\hline 0 & 42 & 48 & 0.04 \\
\hline 1 & 25 & 26 & \\
\hline$\geq 2$ & 33 & 26 & \\
\hline \multicolumn{4}{|l|}{ Tonsillitis } \\
\hline 0 & 46 & 55 & 0.007 \\
\hline 1 & 26 & 21 & \\
\hline$\geq 2$ & 28 & 24 & \\
\hline \multicolumn{4}{|l|}{ Laryngitis } \\
\hline 0 & 91 & 94 & 0.06 \\
\hline$\geq 1$ & 9 & 6 & \\
\hline \multicolumn{4}{|c|}{ Common cold } \\
\hline $0-1$ & 23 & 29 & 0.05 \\
\hline $2-3$ & 25 & 28 & \\
\hline $4-5$ & 21 & 18 & \\
\hline$\geq 6$ & 31 & 25 & \\
\hline
\end{tabular}

*: children who left practices at age $<5$ yrs $(\mathrm{n}=301)$ were excluded, since not all morbidity data of the first 5 years of life were available; \#: number of episodes of respiratory disease.

Table 3. - Comparison between study group $(n=551)$ and the nonrespondents $(n=375)$

\begin{tabular}{|c|c|c|c|}
\hline $\begin{array}{l}\text { Recent respiratory } \\
\text { illnesses* } \\
(1985-1989)\end{array}$ & $\begin{array}{l}\text { Study } \\
\text { group } \\
\%\end{array}$ & Nonrespondents & p-value \\
\hline Asthma & 4 & 3 & 0.47 \\
\hline Acute bronchitis & 7 & 3 & 0.03 \\
\hline Pneumonia & 2 & 2 & 0.78 \\
\hline Hay fever & 11 & 7 & 0.04 \\
\hline Common cold & 34 & 32 & 0.21 \\
\hline Laryngitis & 1 & 1 & 0.78 \\
\hline Tonsillitis & 11 & 10 & 0.64 \\
\hline Otitis media & 11 & 10 & 0.70 \\
\hline
\end{tabular}

*: at least one episode.

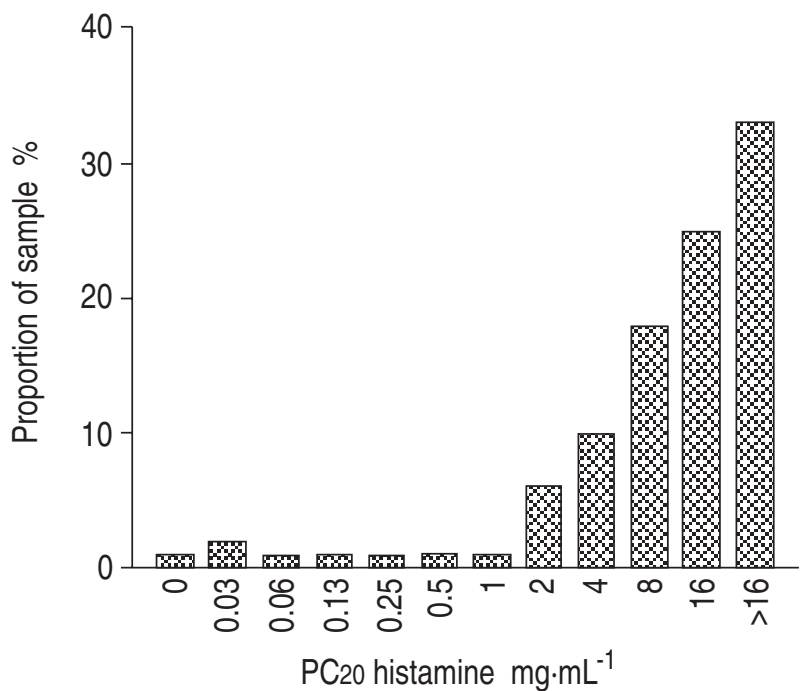

Fig. 2. - Frequency histogram of the values of $\mathrm{PC} 20$ histamine found in the study group. $\mathrm{PC}_{20}$ was measured using the shortened version of the tidal breathing method, according to the European Respiratory Society (ERS) standardized lung function testing. Forty two percent of this population has a $\mathrm{PC} 20 \leq 8 \mathrm{mg} \cdot \mathrm{mL}^{-1}$. $\mathrm{PC} 20$ : provocative concentration of histamine producing a $20 \%$ decrease in forced expiratory volume in one second.

fever), than in the nonhyperresponsive group and in the asymptomatic hyperresponsive group. No differences were found for sex, age, social class, family history of asthma and smoking behaviour between symptomatic BHR, asymptomatic BHR and non-BHR. Multiple logistic regression analysis showed that acute bronchitis in early childhood, allergy and airways obstruction were independently related to BHR.

When $\mathrm{PC}_{2} 0$ values of 4.0 and $2.0 \mathrm{mg} \cdot \mathrm{mL}^{-1}$ histamine were chosen as cut-off points for BHR, the overall prevalence of BHR was 24 and 14\%, respectively; with 60 and $53 \%$, respectively, being asymptomatic (14 and 7\%, respectively of the whole population). These more restrictive criteria did not essentially change the correlation between BHR and early childhood morbidity, nor between BHR and the other factors examined; furthermore, the differences between asymptomatic and symptomatic BHR with respect to the associations with these factors remained the same.

For those who achieved a $20 \%$ fall in FEV1 during bronchial challenge $\left(\mathrm{PC} 20 \leq 16 \mathrm{mg} \cdot \mathrm{mL}^{-1}\right.$ histamine; $\mathrm{n}=369$, $67 \%$ of the study group) no correlation was found between baseline FEV1\% pred and $\log \left(\mathrm{PC}_{20}+1\right)$ (Spearman's rank correlation coefficient $=0.04)$.

\section{Discussion}

The prevalence of BHR, defined by a $\mathrm{PC} 20 \leq 8 \mathrm{mg} \cdot \mathrm{mL}^{-1}$, in this sample of adolescents and young adults was $42 \%$, of which $70 \%$ were asymptomatic. This study indicated a relationship between BHR in adolescence and young adulthood and LRTI in early childhood for subjects with symptomatic BHR, but not for those with asymptomatic BHR. No differences were found with respect to personal and clinical characteristics related to asthma between asymptomatic subjects with BHR and those without BHR. However, symptomatic BHR differed strongly from asymptomatic BHR in this regard. 
Table 4. - Respiratory illnesses in the first 5 yrs of life $(n=551)$ in relation to BHR at 10-23 yrs of age

\begin{tabular}{|c|c|c|c|c|c|c|c|}
\hline \multirow[t]{2}{*}{$\begin{array}{l}\text { Respiratory } \\
\text { illnesses } \\
\text { at age } 0-4 \text { yrs }\end{array}$} & \multirow[b]{2}{*}{$\mathrm{n}$} & \multicolumn{2}{|c|}{$\begin{array}{c}\text { All hyperresponsive } \\
(\mathrm{n}=232 ; 42 \%) \\
\text { vs nonhyperresponsive } \\
\text { subjects } \\
(\mathrm{n}=319 ; 58 \%)\end{array}$} & \multicolumn{2}{|c|}{$\begin{array}{c}\text { Symptomatic\# } \\
\text { hyperresponsive } \\
(\mathrm{n}=70 ; 13 \%) \text { vs } \\
\text { nonhyperresponsive } \\
\text { subjects }\end{array}$} & \multicolumn{2}{|c|}{$\begin{array}{c}\text { Asymptomatic } \\
\text { hyperresponsive } \\
(\mathrm{n}=162 ; 29 \%) \text { vs } \\
\text { nonhyperresponsive } \\
\text { subjects }\end{array}$} \\
\hline & & $\mathrm{RR}$ & $95 \%$ CI & $\mathrm{RR}$ & $95 \%$ CI & $\mathrm{RR}$ & $95 \%$ CI \\
\hline Asthma & 22 & 1.0 & $0.6-1.6$ & 1.6 & $0.7-3.4$ & 0.7 & $0.3-1.6$ \\
\hline Acute bronchitis & 200 & $1.3 *$ & $1.0-1.5$ & $2.0 * *$ & $1.3-3.0$ & 1.1 & $0.9-1.5$ \\
\hline Pneumonia & 46 & 1.0 & $0.7-1.4$ & 1.3 & $0.7-2.5$ & 0.8 & $0.5-1.4$ \\
\hline Hay fever & 15 & 0.6 & $0.3-1.5$ & 0.9 & $0.2-3.1$ & 0.5 & $0.1-1.6$ \\
\hline $\begin{array}{l}\text { Common cold } \\
\text { ( } \geq 4 \text { episodes) }\end{array}$ & 277 & 1.0 & $0.8-1.2$ & 1.0 & $0.6-1.5$ & 0.9 & $0.7-1.1$ \\
\hline Laryngitis & 48 & 1.3 & $1.0-1.8$ & 1.7 & $0.9-3.1$ & 1.3 & $0.9-1.9$ \\
\hline Tonsillitis & 301 & 1.0 & $0.9-1.3$ & 0.8 & $0.5-1.2$ & 1.2 & $0.9-1.5$ \\
\hline Otitis media & 319 & 0.9 & $0.8-1.1$ & 1.2 & $0.8-1.9$ & 0.9 & $0.7-1.1$ \\
\hline
\end{tabular}

Relative risk (RR) and 95\% confidence interval (95\% CI) for all subjects with bronchial hyperresponsiveness (BHR), defined as $\mathrm{PC} 20 \leq 8.0 \mathrm{mg} \cdot \mathrm{mL}^{-1}$, for those with symptomatic BHR and for those with asymptomatic BHR, compared with nonhyperresponsive subjects. \#: in case of an affirmative answer to at least one of the questions on chronic respiratory symptoms; $¥:$ those who presented at least one episode, unless otherwise indicated. PC20: provocative concentration of histamine causing a $20 \%$ decrease in forced expiratory volume in one second. *: $\mathrm{p}<0.05 ; * *: \mathrm{p}<0.01$.

Table 5. - Asymptomatic bronchial hyperresponsiveness (BHR) and symptomatic\# BHR compared with non-BHR and with each other with respect to subject and clinical characteristics

\begin{tabular}{|c|c|c|c|c|c|c|c|c|}
\hline \multirow[t]{2}{*}{$\begin{array}{l}\text { Personal and } \\
\text { clinical } \\
\text { characteristics } \\
(\mathrm{n}=551)\end{array}$} & \multirow[b]{2}{*}{$\mathrm{n}^{+}$} & \multirow[b]{2}{*}{$\%$} & \multicolumn{2}{|c|}{$\begin{array}{c}\text { Asymptomatic } \\
\text { hyperresponsive } \\
(\mathrm{n}=162) v s \\
\text { nonhyperresponsive } \\
\text { subjects }(\mathrm{n}=319)\end{array}$} & \multicolumn{2}{|c|}{$\begin{array}{c}\text { Symptomatic } \\
\text { hyperresponsive } \\
(\mathrm{n}=70) v s \\
\text { nonhyperresponsive } \\
\text { subjects }(\mathrm{n}=319)\end{array}$} & \multicolumn{2}{|c|}{$\begin{array}{c}\text { Symptomatic } \\
\text { hyperresponsive } \\
(\mathrm{n}=70) \text { vs asympto- } \\
\text { matic hyperresponsive } \\
\text { subjects }(162)\end{array}$} \\
\hline & & & OR & $95 \% \mathrm{CI}$ & OR & $95 \% \mathrm{CI}$ & OR & $95 \% \mathrm{CI}$ \\
\hline $\begin{array}{l}\text { Family history of } \\
\text { asthma }\end{array}$ & 109 & 20 & 1.2 & $0.7-1.9$ & 1.0 & $0.5-1.9$ & 0.8 & $0.4-1.7$ \\
\hline Smoking & 130 & 24 & $0.6^{*}$ & $0.3-0.9$ & 1.0 & $0.6-1.9$ & 1.9 & $1.0-3.6$ \\
\hline Allergy & 163 & 33 & 1.3 & $0.8-2.0$ & $3.4 * * *$ & $2.0-6.0$ & $2.6^{* *}$ & $1.5-4.8$ \\
\hline Airways obstruction & 93 & 17 & 1.5 & $0.9-2.6$ & $3.6 * * *$ & $2.0-6.6$ & $2.4 * *$ & $1.3-4.5$ \\
\hline \multicolumn{9}{|c|}{ Recent respiratory illnesses ${ }^{\dagger}(1985-1989)$} \\
\hline Asthma & 21 & 4 & 0.8 & $0.2-3.3$ & $8.3 * * *$ & $3.1-22.3$ & $9.9 * * *$ & $2.7-36.7$ \\
\hline Acute bronchitis & 36 & 7 & 1.0 & $0.5-2.4$ & $3.0^{* *}$ & $1.3-6.9$ & $2.9 *$ & $1.2-7.5$ \\
\hline Pneumonia & 12 & 2 & 0.8 & $0.2-3.3$ & 1.3 & $0.3-6.5$ & 1.6 & $0.3-9.7$ \\
\hline Hay fever & 60 & 11 & 0.8 & $0.4-1.6$ & $3.8 * * *$ & $2.0-7.3$ & $4.8 * * *$ & $2.2-10.6$ \\
\hline Common cold & 219 & 40 & 1.1 & $0.8-1.6$ & 1.6 & $1.0-2.7$ & 1.5 & $0.8-2.6$ \\
\hline Laryngitis & 5 & 1 & - & $-\$$ & $7.2 *$ & $1.2-44.0$ & - & $-\$$ \\
\hline Tonsillitis & 58 & 11 & 0.6 & $0.3-1.2$ & 1.0 & $0.4-2.2$ & 1.6 & $0.6-4.2$ \\
\hline Otitis media & 57 & 11 & 0.8 & $0.4-1.5$ & 1.1 & $0.5-2.4$ & 1.4 & $0.6-3.5$ \\
\hline
\end{tabular}

BHR was defined as a $\mathrm{PC}_{20} \leq 8 \mathrm{mg} \cdot \mathrm{mL}^{-1}$. $\$$ : missing 59 subjects. Odds Ratio (OR) and $95 \%$ confidence interval (95\% CI) for all subjects $(\mathrm{n}=551)$ with asymptomatic BHR, compared with nonhyperresponsive subjects, and for those with symptomatic BHR compared with nonhyperresponsive subjects and with asymptomatic hyperresponders, respectively. \#: in case of an affirmative answer to at least one of the questions on chronic respiratory symptoms; +: numbers and percentages refer to the whole population $(\mathrm{n}=551) ; \uparrow:$ at least one episode; \$: none of those with asymptomatic BHR presented laryngitis in 1985-1989. PC20: provocative concentration of histamine causing a $20 \%$ decrease in forced expiratory volume in one second. *: $\mathrm{p}<0.05 ; * *: \mathrm{p}<0.01 ; * * *$ : $\mathrm{p}<0.001$.

These findings are not consistent with the hypothesis that asymptomatic BHR constitutes a link between early childhood LRTI and asthma in later life.

The present survey produced a high rate of BHR, higher than found in several other studies but not uncommon in comparable populations. BHR prevalence in random population studies ranges $4-64 \%$ [3-5, 23, $26]$. These studies differ in the following factors: the prevalence of asthma and other atopic diseases; the age of the groups; the method used to measure bronchial responsiveness; and the threshold value for hyperresponsiveness. In the present group of subjects, selected from the records of general practices only on the basis of date of birth, the prevalence of asthma and hay fever, diagnosed during the 5 yrs preceding this study, was $4 \%$ and $11 \%$, respectively. However, underdiagnosis in general practice has also been reported in many studies and has been shown in this study group [27]. The incidence of BHR in the present study lies between that found by COCKCROFT et al. [23] (64\% of a group of 300 students aged 20-29 yrs, with a PC20 $\leq 8.0$ $\left.\mathrm{mg} \cdot \mathrm{mL}^{-1}\right)$, and BACKER et al. [28] (16\% of 527 subjects aged 7-16 yrs, with a PC20 $\left.\leq 8.0 \mathrm{mg} \cdot \mathrm{mL}^{-1}\right)$. TRIGG et al. [29] studied 366 subjects, recruited from four general practices in the UK, and performed standardized methacholine challenges. In the UK, persons are included in the registers of general practitioners on the same basis as in the Netherlands. They found a prevalence of BHR 
(defined by $\mathrm{PC} 20$ methacholine $\leq 2 \mathrm{mg} \cdot \mathrm{mL}^{-1}$ ) of $23 \%$. However, if they had applied the criterion of $\mathrm{PC}_{20} \leq 8$ $\mathrm{mg} \cdot \mathrm{mL}^{-1}$ to their data, they would have found a prevalence of $38 \%$ in a population recruited in a way comparable to ours. TRIGG et al. [29] also quoted an Australian study reporting a $35 \%$ prevalence of BHR in a population of college students. Absence of symptoms has been found by others in a substantial proportion of hyperresponsive children $(41 \% ; 7 \%$ of the total population) [5], and adults (59\%; 14\% of the total population) [4]. Consequently, we consider that the prevalence of BHR of $42 \%$ in our study group is high, but not unprecedented.

The questionnaire may have been biased in its Dutch translation towards the "Dutch hypothesis", by focusing not only on asthma but also on COPD, especially with the questions on persistent chronic cough. This may have caused underreporting of asthma symptoms. However, chronic cough can be the sole clinical manifestation of asthma, and COPD is rare in the age category of our study group.

The sample of the present study was selected by date of birth only from registers of general practitioners. The subjects were adolescents and young adults, who volunteered to take part in the screening. Self-selection may have been a factor of influence, with "healthier" subjects less likely to participate. The comparison between our study group and the original birth cohorts did not reveal important differences. Therefore, it is unlikely that selection bias was an important cause of the high prevalence of BHR found in this study. It was probably not the result of recent respiratory infections either, since in that case the histamine challenge test was postponed for 6 weeks. Most tests were performed in December and January, thus avoiding the influence of the grass pollen season.

A standardized method for testing BHR was used [20], and the recommendations issued for its use were followed exactly. Nebulizers and spirometers were calibrated regularly. Data from inadequately performed forced expiratory manoeuvres were excluded from the analysis. The field testing was performed by trained personnel, supervised by the university lung function laboratory. As a consequence, we consider it unlikely that the high prevalence of BHR is due to poor methodology.

\section{Early childhood LRTI and subsequent symptomatic or asymptomatic BHR}

Acute bronchitis in early childhood was related to BHR at 10-23 yrs of age, a finding consistent with other studies relating early childhood respiratory illness and subsequent BHR [30, 31]. It still has to be established whether this relationship results from early childhood LRTI, predisposing children to later BHR by triggering causal mechanisms, or whether the childhood LRTI are an early expression of BHR. It should be realized that, in this study, the classification "acute bronchitis" includes bronchiolitis, which is related to subsequent pulmonary function abnormalities and asthma [32]. However, this cannot be explored in the present study, due to lack of specific information. "Acute bronchitis" may be liable to misclassification: asthma-like symptoms, registered as acute bronchitis, could have been a first manifestation of asthma.

BHR should not be regarded as a specific entity in itself. It can merely result from airway narrowing. In the present study, no correlation was found between $\mathrm{PC}_{20}$ and baseline FEV1, which is in accordance with TWENTYMAn et al. [33]. In our view, submucosal changes are more important determinants for BHR, as reflected in the hypothesis raised at the start of this study. However, our study did not support this hypothesis, as did a recent study in adolescents [10]. The latter study used a more restrictive definition of BHR, but application of more restrictive definitions of BHR in our analysis, with lower histamine thresholds, did not change the results.

\section{Characteristics of symptomatic and asymptomatic BHR}

In the present study group, the considerable differences between asymptomatic and symptomatic BHR, and the similarities of the characteristics of asymptomatic BHR and non-BHR subjects, suggest that asymptomatic BHR is an entity, completely independent of asthma. Therefore, this does not support the hypothesis that asymptomatic BHR precedes the development of asthma [9, $10]$.

The present analysis does not allow firm conclusions regarding asymptomatic BHR as a risk factor for future asthma. To that end, further longitudinal studies are needed, with a close follow-up of asymptomatic BHR.

It has been suggested that hyperresponsive subjects may be asymptomatic because of poor recognition of symptoms [8]. However, in the present study, symptomatic and asymptomatic hyperresponsive subjects also differed in a number of characteristics that are distinct from symptom perception. Therefore, perception does not seem to be a determining factor in explaining the difference between the two forms of BHR.

BHR in this and other surveys was assessed at one moment in time. The reproducibility of the histamine challenge test is good [20], but bronchial responsiveness can vary considerably with time due to external factors [6, 34]. In general, the group with asymptomatic BHR had lower levels of BHR than the group with symptomatic BHR, and this mild BHR may disappear [6]. However, this does not seem an important factor, as the application of more restrictive definitions of BHR did not essentially change the results.

In summary, this study does not support the hypothesis that asymptomatic bronchial hyperresponsiveness constitutes a link between early childhood lower respiratory illnesses and asthma in later life, nor for asymptomatic bronchial hyperresponsiveness to be a risk for subsequent asthma.

Acknowledgements: The authors are indebted to the participants in this study and their parents for their cooperation, and the general practitioners and the practice assistants of the CMR practices for their assistance. They gratefully acknowledge the help of L.M. Bierman, H. Janssen, L. Klerks, P. Pennings, C.B. Poelen and T.J.M. Teunissen in measuring the subject's lung function and bronchial responsiveness. They are also very grateful to W. Tiersma for his computer assistance and to J. Lummen for his linguistic comments. 


\section{References}

1. Hall WJ, Hall CB, Speers DM. Respiratory syncytial virus infection in adults: clinical, virologic and serial pulmonary function studies. Ann Intern Med 1978; 88: 203-205.

2. Lemanske RF Jr, Dick EC, Swenson CA, et al. Rhinovirus upper respiratory infection increases airway hyperreactivity and late asthmatic responses. J Clin Invest 1989; 83: $1-10$.

3. Salome CM, Peat JK, Britton WJ, Woolcock AJ. Bronchial hyperresponsiveness in two populations of Australian schoolchildren. 1. Relation to respiratory symptoms and diagnosed asthma. Clin Allergy 1987; 17: 271-281.

4. Rijcken B, Schouten JP, Weiss ST, Speizer FE, Van der Lende R. The relationship of nonspecific bronchial responsiveness to respiratory symptoms in a random population sample. Am Rev Respir Dis 1987; 136: 62-68.

5. Pattemore PK, Asher MI, Harrison AC, Mitchell EA, Rea HH, Stewart AW. The interrelationship among bronchial hyperresponsiveness, the diagnosis of asthma, and asthma symptoms. Am Rev Respir Dis 1990; 142: 549-554.

6. Peat JK, Salome CM, Sedgwick CS, Kerrebijn J, Woolcock AJ. A prospective study of bronchial hyperresponsiveness and respiratory symptoms in a population of Australian schoolchildren. Clin Exp Allergy 1989; 19: 299-306.

7. de Gooijer A, Brand PLP, Gerritsen J, Koëter GH, Postma DS, Knol K. Changes in respiratory symptoms and airway hyperresponsiveness after 27 years in a populationbased sample of school children. Eur Respir J 1993; 6: 848-854.

8. Brand PLP, Rijcken B, Schouten JP, Koëter GH, Weiss ST, Postma DS. Perception of airway obstruction in a random population sample: relation to airway hyperresponsiveness in the absence of respiratory symptoms. Am Rev Respir Dis 1992; 146: 396-401.

9. Hopp RJ, Townley RG, Biven RE, Bewtra AK, Nair NM. The presence of airway reactivity before the development of asthma. Am Rev Respir Dis 1990; 141: 2-8.

10. Zhong NS, Chen RC, Ou Yang M, Wu ZY, Zheng JP, Li YF. Is asymptomatic bronchial hyperresponsiveness an indication of potential asthma? A two year followup of young students with bronchial hyperresponsiveness. Chest 1992; 102: 1104-1109.

11. Sherman CB, Tosteson TD, Tager IB, Speizer FE, Weiss ST. Early childhood predictors of asthma. Am J Epidemiol 1990; 132: 83-95.

12. Kolnaar BGM, Van Lier A, Van den Bosch WJHM, et al. Asthma in adolescents and young adults: relationship with early childhood respiratory morbidity. $\mathrm{Br}$ J Gen Pract 1994; 44: 73-78.

13. van Weel C. Validating long-term morbidity recording. J Epidemiol Commun Health 1995; 49 (Suppl.): 29-32.

14. van Weel C. Chronic diseases in general practice: longterm dimension. Eur J Gen Pract 1996; 2: 17-21.

15. van Weel C, van den Bosch WJHM, van den Hoogen HJM, Smits AJA. Development of respiratory illness in childhood: a longitudinal study in general practice. $J R$ Coll Gen Pract 1987; 37: 404-408.

16. Ferris BG. Epidemiology standardization project. II. Recommended respiratory disease questionnaires for use with adults and children in epidemiologic research. Am Rev Respir Dis 1978; 118 (Suppl.): 7-53.

17. Brunekreef B, Groot B, Rijcken B, Hoek G, Steenbekkers A, De Boer A. Reproducibility of childhood respiratory symptom questions. Eur Respir J 1992; 5: 930-955.
18. Dompeling E, Van Schayck CP, Folgering H, Van den Hoogen HJM, van Weel C. Accuracy, precision and linearity of the portable flow-volume meter, Microspiro HI-298. Eur Respir J 1991; 4: 612-615.

19. Zapletal A, Samanek M, Paul T. Lung function in children and adolescents. In: Herzog H, ed. Methods, Reference Values. Basel, S. Karger AG, 1987; pp. 1-220.

20. Working party of the European Respiratory Society. Standardized lung function testing. Eur Respir J 1993; 6 (Suppl. 16): 5-100.

21. Matricardi PM, Nisini R, Pizzolo JG, Amelio R. The use of Phadiatop in mass-screening programmes of inhalant allergies: advantages and limitations. Clin Exp Allergy 1991; 20: 151-155.

22. Backer V, Groth S, Dirksen A, et al. Sensitivity and specificity of the histamine challenge test for the diagnosis of asthma in an unselected sample of children and adolescents. Eur Respir J 1991; 4: 1093-1100.

23. Cockcroft DW, Berscheid BA, Murdock KY. Unimodal distribution of bronchial responsiveness to inhaled histamine in a random human population. Chest 1983; 83: 751-754.

24. Tattersfield AE, Higgins BG. Bronchial reactivity in the community. Eur Respir J 1988; 1: 476-491.

25. Ryan G, Latimer KM, Dolovich J, Hargreave FE. Bronchial responsiveness to histamine: relation to diurnal variation in peak flow rate, improvement after bronchodilator usage, and airway calibre. Thorax 1982; 37: 423-429.

26. Zhong NS, Chen RC, Ou-yang M, Wu JY, Fu WX, Shi LJ. Bronchial hyperresponsiveness in young students of southern China: relation to respiratory symptoms, diagnosed asthma and risk factors. Thorax 1990; 45: 860865.

27. Kolnaar BGM, Beissel E, Van den Bosch WJHM, Folgering $\mathrm{H}$, Van den Hoogen HJM, Van Weel C. Asthma in adolescents and young adults: screening outcome versus diagnosis in general practice. Family Practice 1994; 11 : 133-140.

28. Backer V, Dirksen A, Bach-Mortensen N, et al. The distribution of bronchial responsiveness to histamine and exercise in 527 children and adolescents. J Allergy Clin Immunol 1991; 88: 68-76.

29. Trigg CJ, Bennett JB, Tooley M, Sibbald B, D'Souza MF, Davies RJ. A general practice based survey of bronchial hyperresponsiveness and its relation to symptoms, sex, age, atopy and smoking. Thorax 1990; 45: 866-872.

30. Weiss ST, Tager IB, Munoz A, Speizer FE. The relationship of respiratory infections in early childhood to the occurrence of increased levels of bronchial responsiveness and atopy. Am Rev Respir Dis 1985; 131: 573-578.

31. Peat JK, Salome CM, Woolcock AJ. Factors associated with bronchial hyperresponsiveness in Australian adults and children. Eur Respir J 1992; 5: 921-929.

32. Pullan CR, Hey EN. Wheezing, asthma and pulmonary dysfunction 10 years after infection with respiratory syncytial virus in infancy. Br MedJ 1982; 284: 1665-1669.

33. Twentyman OP, Hood SV, Holgate ST. Does baseline airway calibre affect measurement of airway responsiveness to histamine? J Appl Physiol 1993; 74: 3034-3039.

34. Britton JR, Burney PGJ, Chinn S, Papacosta AO, Tattersfield AE. The relation between change in airway reactivity and change in respiratory symptoms and medication in a community study. Am Rev Respir Dis 1988; 138: 530-534. 